\title{
Os números da licenciatura em matemática: políticas públicas em foco
}

Renato Santos Araujo raraujo.brasil@gmail.com 0000-0003-0110-6221

Universidade Federal de Sergipe, São Cristóvão

Deise Miranda Vianna deisevia@gmail.com 0000-0001-5846-0841

Universidade Federal do Rio de Janeiro, Rio de Janeiro

\section{RESUMO}

A necessária ampliação da educação básica, realizada pela Lei no 9.394 (BRASIL, 1996), levou o país a estatísticas preocupantes no que se refere à falta de professores. Nesse contexto, este trabalho pretende apresentar e discutir alguns dados sobre os cursos de Licenciatura em Matemática por meio do levantamento e da análise de documentos oficiais para a realização de uma pesquisa documental com abordagem quantitativa. As fontes de dados utilizadas foram as Sinopses Estatísticas do Ensino Superior, publicadas pelo Instituto Nacional de Estudos e Pesquisas Anísio Teixeira (INEP/MEC). Os dados serão apresentados por meio de gráficos e as análises farão uso de estatística descritiva. A análise de dados aponta que a política de ensino superior brasileira está apoiada na iniciativa privada, que o Sistema de Seleção Unificada pode ser o responsável pelo aumento dos candidatos nas instituições públicas e que o país triplicou o número de professores de matemática formados, uma vitória. Contudo, enquanto nos demais cursos de nível superior o país observa uma pequena ociosidade de vagas nas instituições públicas, nos cursos de licenciatura o mesmo não acontece. Também observou-se que as taxas de evasão no curso de Licenciatura em Matemática foram altas. Por último conclui-se que a dita ampliação dos cursos de formação de professores não ocorreu no caso da matemática, visto que seu crescimento sequer acompanhou a expansão do ensino superior brasileiro.

PALAVRAS-CHAVE: Formação de professores. Ensino de matemática. Políticas públicas de Educação. 


\section{INTRODUÇÃO}

No século passado as políticas públicas voltadas para a formação de professores contaram "com a oposição dos professores militantes nas diversas entidades científicas [...], especialmente as IES públicas" (BITTAR; NOGUEIRA, 2015, p. 267). A divergência era contra a Reforma Universitária, Lei no 5.540/1968 (BRASIL, 1968), e a mudança da formação mínima exigida para o exercício do magistério, Lei no 5.692/1971 (BRASIL, 1971), que criaram as Licenciaturas Curtas. As críticas surgiram nas 27a e 28a Reuniões Anuais da Sociedade Brasileira para o Progresso da Ciência SBPC (1975 e 1976), no XI Seminário de Assuntos Universitários em Brasília (1978), na 31ạ Reunião Anual da SBPC (1979), nos III e IV Simpósios Nacionais de Ensino de Física (1976 e 1979), no Colóquio Brasileiro de Matemática (1977) e na 32a Reunião Anual da SBPC (1980) (SBPC, 1981).

Esses movimentos, contudo, não conseguiram impedir as transformações e a partir dessa época o país passou a formar professores de matemática em cursos aligeirados com o objetivo de reduzir o número de docentes leigos nas escolas. $O$ resultado obtido foi o declínio da qualidade da formação de professores (VILLANI; PACCA; FREITAS, 2009).

Hoje a formação de professores para a educação básica ocorre no ensino superior, em cursos de Licenciatura plena, tem a Educação Básica como referência e deve considerar as diretrizes gerais e as normas nacionais pertinentes instituídas pelo Ministério da Educação e o Conselho Nacional de Educação (ARAUJO; VIANNA, 2010).

A necessária ampliação da educação básica, realizada pela Lei no 9.394 (BRASIL, 1996), levou o país a estatísticas preocupantes. Houve a volta de propostas emergenciais que se apresentam como retrocessos para a formação de professores, tais como aquelas apresentadas por Ibañez, Ramos e Hingel (2007). Isto é, a carência de professores motiva, mais uma vez, transformações políticas no âmbito da educação. E desta vez a solução passa pela ampliação das vagas nos cursos de Licenciatura em Matemática.

Aliado ao problema quantitativo, uma nova cultura, contextualizada na globalização, sob uma política econômica neoliberal e permeada pelas tecnologias da informação e da comunicação, tem mudado, qualitativamente, o problema da formação do professor e do ensino de matemática. E isso tem levado as políticas públicas a construírem relações dicotômicas entre os conteúdos da matéria a ser ensinada e aqueles oriundos das relações professor-aluno-sociedade (FIORENTINI, 2008).

O ensino de matemática na atualidade busca sair do paradigma tradicional, livresco e caracterizado pela memorização de demonstrações. Os Parâmetros Curriculares Nacionais (BRASIL, 2000) apontam para a necessidade de desenvolver alunos com diferentes motivações, interesses e capacidades. Ou seja, a meta não é formar o cientista, mas criar condições para a inserção dos estudantes em um mundo ágil e desenvolver neles habilidades e competências que deles serão exigidas em sua vida social e profissional. O papel formativo da matemática desenvolve pensamentos que transcendem ela própria. Do ponto de vista instrumental, não se trata do ensino de técnicas, mas de dar ao estudante a segurança e a iniciativa para adaptá-las a diferentes contextos. Como ciência, é importante que seu ensino ajude os alunos a compreender os sistemas de 
validação das técnicas aplicadas. No âmbito da aprendizagem contínua, a matemática desempenha importante papel, assim como os outros conhecimentos da educação básica, para que o estudante possa estar preparado para um mundo em transformação que tornam "ultrapassadas a maior parte das competências adquiridas por uma pessoa ao início de sua vida profissional" (p. 41). Esses aspectos apontam para novos objetivos para o ensino da matemática no ensino médio:

\begin{abstract}
Compreender os conceitos, procedimentos e estratégias matemáticas que permitam a ele desenvolver estudos posteriores e adquirir uma formação científica geral; aplicar seus conhecimentos matemáticos a situações diversas, utilizando-os na interpretação da ciência, na atividade tecnológica e nas atividades cotidianas; Analisar e valorizar informações provenientes de diferentes fontes, utilizando ferramentas matemáticas para formar uma opinião própria que lhe permita expressar-se criticamente sobre problemas da Matemática, das outras áreas do conhecimento e da atualidade; Desenvolver as capacidades de raciocínio e resolução de problemas, de comunicação, bem como o espírito crítico e criativo; Utilizar com confiança procedimentos de resolução de problemas para desenvolver a compreensão dos conceitos matemáticos; Expressar-se oral, escrita e graficamente em situações matemáticas e valorizar a precisão da linguagem e as demonstrações em Matemática; Estabelecer conexões entre diferentes temas matemáticos e entre esses temas e o conhecimento de outras áreas do currículo; Reconhecer representações equivalentes de um mesmo conceito, relacionando procedimentos associados às diferentes representações; Promover a realização pessoal mediante o sentimento de segurança em relação às suas capacidades matemáticas, o desenvolvimento de atitudes de autonomia e cooperação (BRASIL, 2000 p.42).
\end{abstract}

E é certo que sem a devida formação, o professor não conseguirá alcançar esses objetivos. Assim, é responsabilidade do Estado garantir que essa formação ocorra com a quantidade e a qualidade necessárias. Um exemplo de uma ação do Estado com o objetivo de ampliar e melhor formar os professores de Matemática é a Rede do Mestrado Profissional em Matemática em Rede Nacional (PROFMAT). Ela está estruturada em todo o país e tem como objetivo promover a formação continuada de professores das redes públicas de educação, no nível de pósgraduação stricto, por meio da integração de Instituições de Ensino Superior participantes do Sistema Universidade Aberta do Brasil e de Instituições Públicas de Ensino Superior que objetivam integração à UAB (CAPES, 2010).

Essa política, segundo Caldatto, Pavanello e Fiorentini (2016), tem gerado pouco impacto do ponto de vista qualitativo. Isso ocorre porque seu currículo não vincula os elementos que o compõem à prática do professor de Matemática da Educação Básica e também porque há um hiato entre o material didático utilizado nas disciplinas e o processo de modelação do currículo.

Políticas públicas para a formação de professores de matemática não são exclusividade dos programas de pós-graduação. No âmbito da graduação, ações também foram implementadas para aumentar o número de licenciados em matemática, como a ampliação da oferta de vagas por meio da modalidade a distância. E avaliações sistemáticas buscaram mensurar aspectos importantes dessa modalidade de ensino. Um exemplo de reflexão se encontra na Universidade Federal de Santa Catarina (FLORES et al., 2010). Nesse caso específico, os autores observaram problemas na falta de espaço nas bibliotecas, de computadores nos polos, da lentidão da rede de computadores e a falta de engajamento para 
planejamento participativo entre os professores. Do ponto de vista pedagógico, as videoconferências tiveram problemas técnicos (som, áudio e transmissão), além de falta de objetivo ou propósito. Os materiais didáticos adotados, por sua vez, foram considerados pouco adequados à modalidade devido à linguagem e sua aplicabilidade. E os recursos humanos, no caso dos tutores, precisavam de melhor formação e remuneração.

De um ponto de vista geral, algumas políticas se propõem à criação de ações (às vezes emergenciais) que visam modificar a realidade da formação de professores. Outras, tratam de alterar processos formativos já existentes. A ação mais contundente realizada pelo governo federal nesse sentido foi a publicação das Diretrizes Curriculares para os Cursos de Matemática (BRASIL, 2001). Sobre esse documento, Junqueira e Manrique (2015) afirmam que se buscou dissolver dicotomias que caracterizam os cursos desde sua criação, como aquelas existentes entre teoria e prática, conteúdos específicos e pedagógicos e a valorização dos cursos de bacharelados em detrimento dos cursos de licenciatura. Nesses documentos existem "movimentos de tensão, ou seja, tentativas de derretimento de sólidos, observados nas várias reformas ocorridas por motivos essencialmente políticos, culturais e econômicos, com a intenção de dar nova forma ao ensino" (JUNQUEIRA; MANRIQUE, 2015, p.633). Contudo, a conclusão das autoras foi que houve a reincidência de quase todos os problemas levantados no século passado.

Conhecer os resultados obtidos pelo conjunto de ações realizadas para sanar a carência de professores é relevante para o desenvolvimento de novas políticas que visem melhorar a qualidade da educação matemática realizada no país. Nesse sentido, esse trabalho pretende apresentar alguns dados sobre os cursos de Licenciatura em Matemática e compará-los com os dados do ensino superior brasileiro. Algumas questões de estudo foram elencadas para nortear as análises. São elas:

Houve uma ampliação real das vagas nos cursos de Licenciatura em Matemática elas ou apenas acompanharam o crescimento do ensino superior brasileiro?

Com a ampliação das vagas nos cursos de Licenciatura em Matemática, o que mais cresceu, ingressos ou vagas ociosas?

O aumento dos concluintes foi proporcional ao crescimento das vagas ou ingressos?

O que pode ser dito a respeito da evasão nos cursos de Licenciatura em Matemática?

\section{METODOLOGIA}

Este trabalho fez uso do levantamento e da análise de documentos para a realização de uma pesquisa documental com abordagem quantitativa. As fontes de dados utilizadas foram as Sinopses Estatísticas do Ensino Superior publicadas pelo Instituto Nacional de Estudos e Pesquisas Anísio Teixeira (INEP) do Ministério da Educação (MEC). O período analisado está compreendido entre os anos de 2000 e 2013. Esse período foi escolhido porque os anos anteriores não separavam o Bacharelado da Licenciatura e as categorias administrativas. 
Os dados serão apresentados por meio de gráficos, permitindo a visualização de padrões no período estudado. As análises fizeram uso de estatística descritiva, procurando descrever e avaliar os dados representativos do objeto de estudo. As vagas ociosas foram obtidas a partir da subtração do número de vagas pelo número de inscritos. As taxas de evasão foram obtidas por meio de metodologias presentes na literatura (NUNES, 2013), foram consideradas apenas as estatísticas sobre os cursos presenciais e desconsiderou-se o caráter público ou privado nesse cálculo. Os modelos matemáticos adotados para se calcular essas taxas são apresentados nas Fórmulas 1, 2 e 3.

Fórmula 1: Modelo adotado pelo Instituto Lobo para o cálculo da evasão.

$$
E_{(n)}=1-\frac{M_{(n+1)}-I_{(n+1)}}{M_{(n)}-C_{(n)}}
$$

Fórmula 2: Modelo adotado pelo Programa Universidade para Todos (PROUNI) para o cálculo da evasão.

$$
E_{(n)}=\frac{M_{(n)}-C_{(n)}+I_{(n+1)}-M_{(n+1)}}{M_{(n)}}
$$

Fórmula 3: Modelo adotado pela Organização para a Cooperação e Desenvolvimento Econômico (OCDE) e pelo Programa de Apoio a Planos de Reestruturação e Expansão das Universidades Federais (REUNI) para o cálculo da evasão.

$$
\mathrm{E}_{(\mathrm{n})}=1-\frac{\mathrm{C}_{(\mathrm{n})}}{\mathrm{I}_{(\mathrm{n}-3)}}
$$

Onde:

$\mathrm{E}=$ taxa de evasão; $\mathrm{M}=$ matrículas; $\mathrm{I}=$ ingressos; $\mathrm{C}=$ concluintes; $\mathrm{n}=$ ano considerado.

\section{RESULTADOS}

\subsection{Vagas}

Ao todo o Brasil ofertou 47,9 milhões de vagas para todas as carreiras no ensino superior. Destas, $74,8 \%$ foram ofertadas na modalidade presencial (a qual cresceu $182,0 \%$ ), sendo que $10,6 \%$ do estão no setor público (com um crescimento igual a $114,1 \%$ ), e $64,2 \%$, na iniciativa privada (com crescimento igual a 199,2\%). A modalidade a distância em 2000 ofertou 6,4 mil vagas e em 2013 esse número passou para 1,6 milhões de vagas para todas as carreiras no ensino superior, conforme pode ser visto na Figura 1. Essa ampliação foi consequência das mudanças legais que permitiram a oferta de educação em modalidades não presenciais com o suporte de novas tecnologias da informação e da comunicação e dos investimentos do governo nessa modalidade. 
Figura 1 - Vagas em todos os cursos de nível superior no Brasil, segundo os anos, a modalidade de ensino e as categorias administrativas.

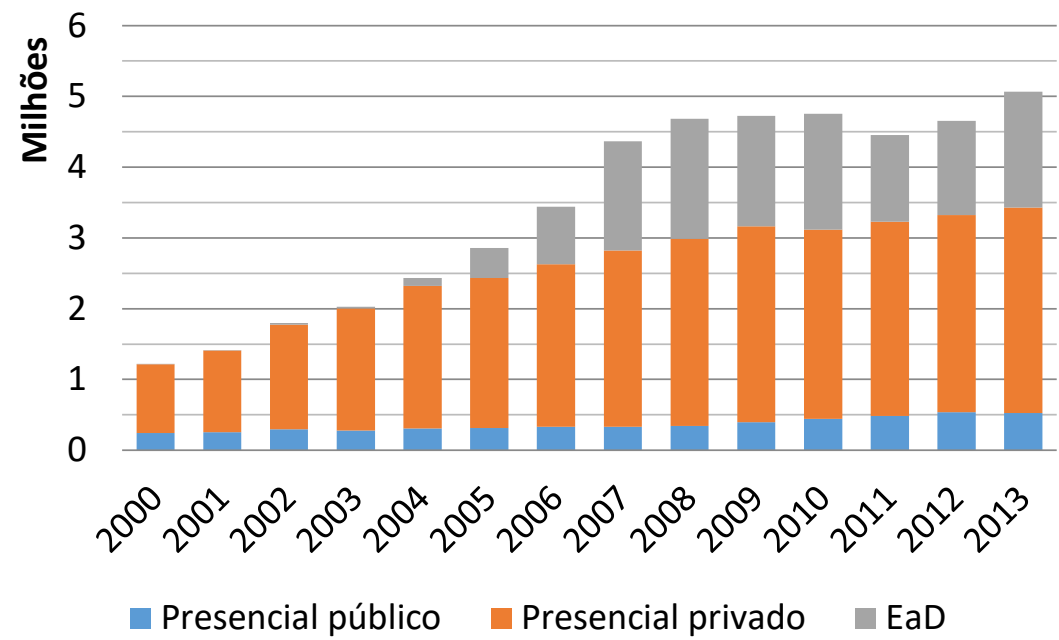

(Fonte: INEP)

Esses dados deixam claro que o ensino superior brasileiro está apoiado na iniciativa privada. Isso é consequência do investimento de recursos públicos nesse setor mediante a renúncia da arrecadação de tributos, por meio de programa Universidade Para Todos (SANTOS FILHO; CHAVES; MORAIS, 2015). Essa política, aliada ao contingenciamento dos recursos para o setor público, fez a participação da iniciativa privada na oferta de vagas crescer de 79,8\% em 2000 para 84,7\% em 2013.

Nos cursos de Licenciatura em Matemática foram ofertadas 813,5 mil vagas ao longo do período estudado, das quais $51,2 \%$ encontravam-se na modalidade presencial, que cresceu 97,6\%. A modalidade a distância, por sua vez, passou de 160 vagas em 2001 para 24,6 mil vagas em 2013, como pode ser visto na Figura 2.

Figura 2 - Vagas nos cursos de Licenciatura em Matemática no Brasil, segundo os anos e a modalidade de ensino.

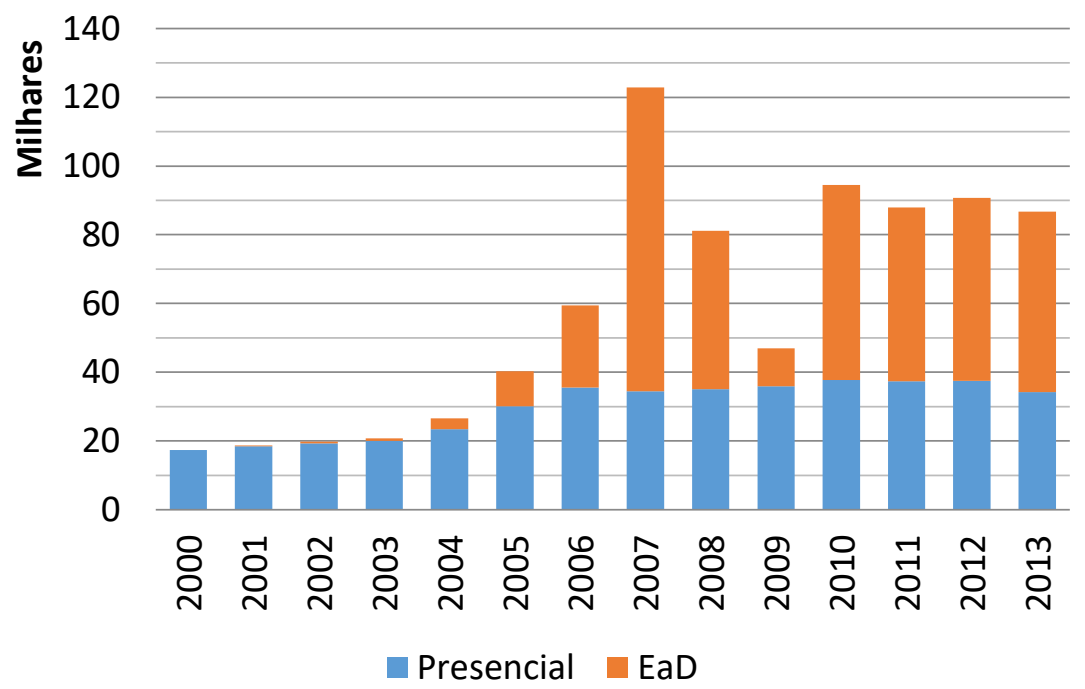


A modalidade a distância, apesar de ser recente no âmbito legal com a sua introdução por meio da Lei no 9.394 (BRASIL, 1996), foi responsável por aproximadamente metade das vagas ofertadas no período. Em 2013, ela já era a modalidade de ensino preferencial para a oferta de vagas para a formação de professores de matemática, tendência oposta àquela observada para as demais carreiras de nível superior. Um aspecto negativo para a formação de professores de matemática está no crescimento da oferta de vagas na modalidade presencial (igual a 97,6\%). Ele foi aproximadamente igual à metade daquele observado no ensino superior presencial brasileiro (igual a 182,0\%). Ou seja, o crescimento sequer acompanhou a ampliação do ensino superior.

\subsection{Candidatos}

Dos 95,8 milhões de candidatos ao ensino superior, 93,0\% buscaram a modalidade presencial, sendo que $48,1 \%$ o fizeram para as instituições públicas e $44,9 \%$, para as privadas. O crescimento de candidatos para as instituições públicas presenciais ocorreu principalmente após o ano de 2009, visto que entre 2000 e 2009 o aumento foi igual a 18,8\% e entre 2010 e 2013 a busca expandiu-se 114,9\%. Nos dois períodos o crescimento foi linear, tal que uma possível explicação para a mudança em 2009 foi a implementação do Sistema de Seleção Unificada (SiSU/MEC). Com relação à iniciativa privada, o crescimento foi aproximadamente linear em todo o período, não sofrendo flutuações relevantes em 2009. Com relação à modalidade a distância, até 2004 o número de candidatos era muito pequeno. Posteriormente os candidatos passaram a ter um crescimento linear até 2009, quando então a curva passou a ter um crescimento cada vez maior (semelhante a uma parábola). Isso pode indicar que o que afetou o crescimento de candidatos para o ensino superior presencial público também influenciou a modalidade a distância, como pode ser visto na Figura 3.

Figura 3 - Candidatos a todos os cursos de nível superior no Brasil, segundo os anos, a modalidade de ensino e as categorias administrativas.

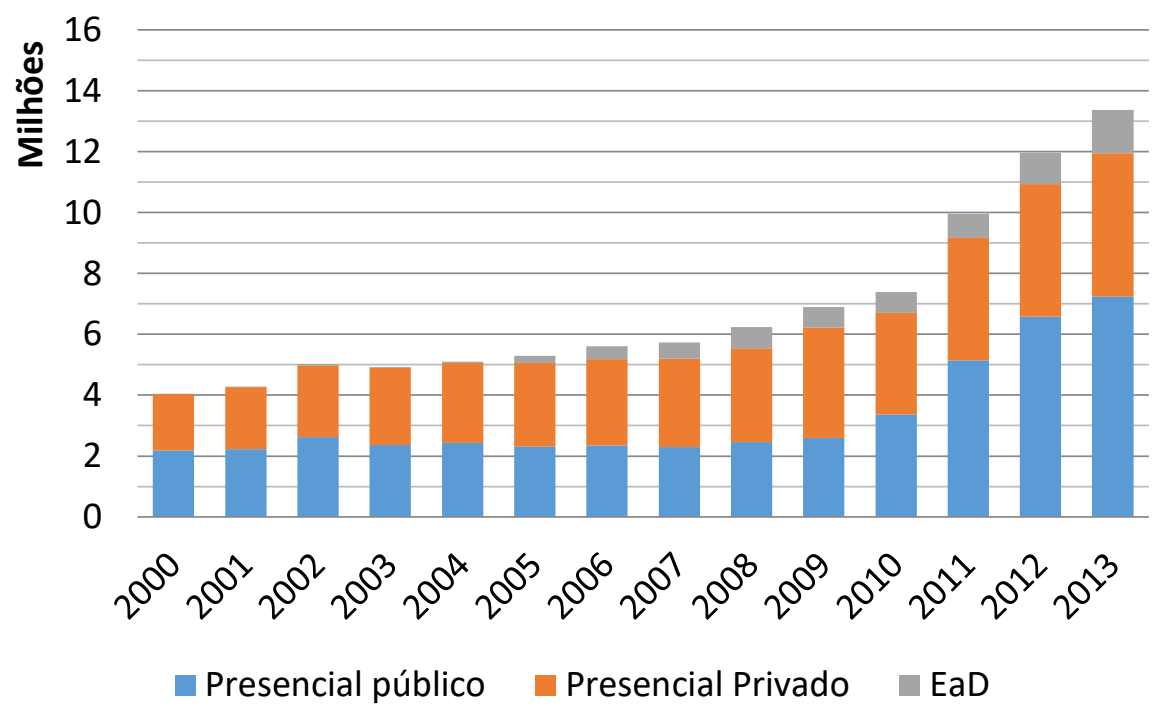


Sobre o curso de Licenciatura em Matemática, dos 1,1 milhões de candidatos, $83,7 \%$ buscaram a modalidade presencial, a qual observou um aumento de $278,0 \%$ ao longo do período. Assim como ocorreu com todos os cursos de ensino superior desenvolvidos no Brasil, nos cursos de licenciatura em Matemática esse aumento ocorreu, principalmente, a partir de 2009, como pode ser observado na Figura 4.

Figura 4 - Candidatos aos cursos de Licenciatura em Matemática no Brasil, segundo os anos e a modalidade de ensino.

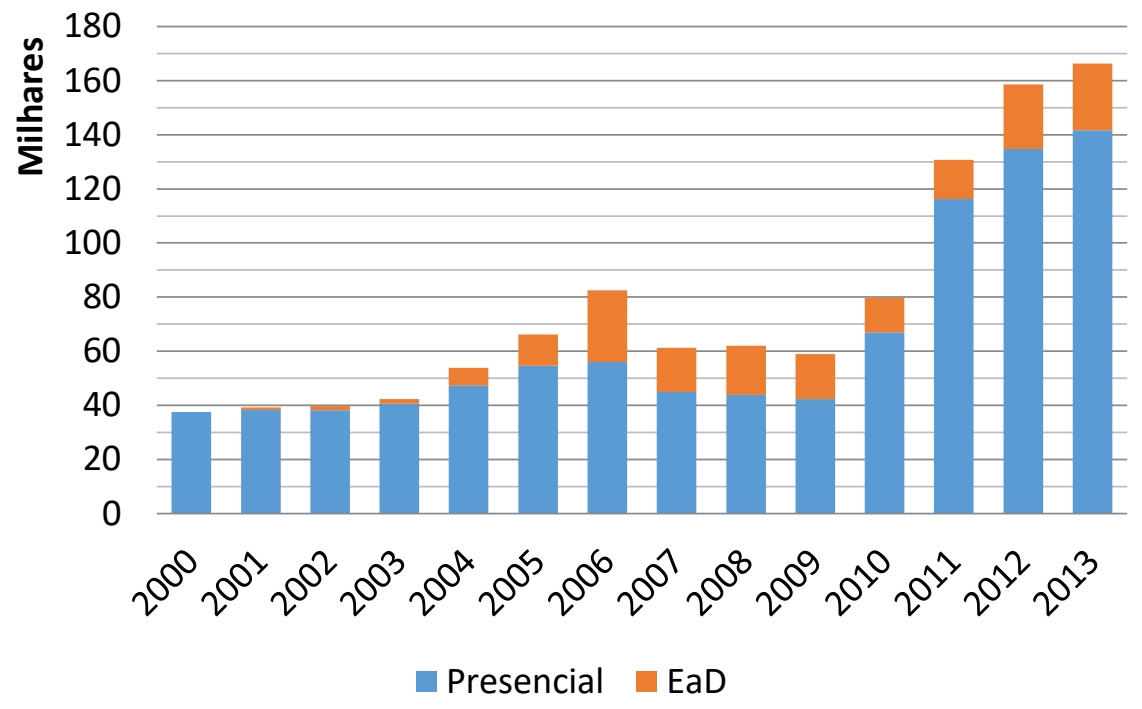

(Fonte: INEP)

O que motivou o aumento de candidatos a partir de 2009 no ensino superior brasileiro presencial também favoreceu o crescimento de candidatos para os cursos presenciais de Licenciatura em Matemática. Analisando-se as políticas públicas implementadas pelo governo federal, o acontecimento mais relevante nesse ano foi a criação do Sistema de Seleção Unificada (SiSU). Esse sistema consiste de uma plataforma online do MEC. O estudante que realizar o Exame Nacional do Ensino Médio (ENEM) pode utilizá-la para se inscrever nas instituições de ensino superior que aderiram à nota do Enem como forma de ingresso, em substituição ao vestibular. Dentre as características que essa política possui que fundamenta a hipótese destacam-se os seguintes aspectos: sua gratuidade, ao contrário dos vestibulares que cobravam valores altos dos candidatos; seu caráter integrador, na medida em que permite ao candidato concorrer às vagas de instituições públicas ou privadas, presenciais ou a distância, às bolsas de estudos ou aos empréstimos do governo federal; e sua função certificadora, pois o ENEM é o exame que permite àqueles que não terminaram a educação básica obter certificados de conclusão ou de proficiência em áreas do ensino médio. Outra consideração importante a ser destacada é a falta de interesse da população na modalidade a distância. Mais de um quarto das vagas ofertadas no ensino superior brasileiro ao longo do período estavam nessa modalidade, mas apenas 7,0\% dos candidatos a buscaram. Nos cursos de Licenciatura em Matemática, onde quase metade das vagas estavam nessa modalidade, menos de um sexto dos candidatos a buscaram, o que levou a uma relação candidato/vaga igual a 0,4. Ou seja, mesmo que todos os candidatos a essa modalidade ingressassem nos cursos de Licenciatura em Matemática, ainda haveriam 221,6 mil vagas ociosas. 


\subsection{Ingressos}

Dos 23,6 milhões de ingressos observados em todas as carreiras de ensino superior, $85,7 \%$ foram realizados na modalidade presencial, sendo que $19,5 \%$ ocorreu no setor público, que cresceu $96,2 \%$, e $66,2 \%$ na iniciativa privada, que aumentou $124,9 \%$. Sobre a modalidade a distância, as categorias administrativas passaram a ser identificadas a partir de 2008 , tal que a partir desse ano observouse uma queda de $79,9 \%$ dos ingressos no setor público e um crescimento de $93,7 \%$ na iniciativa privada, conforme pode ser visualizado na Figura 5.

Figura 5 - Ingressos a todos os cursos de nível superior no Brasil, segundo os anos, a modalidade de ensino e as categorias administrativas.

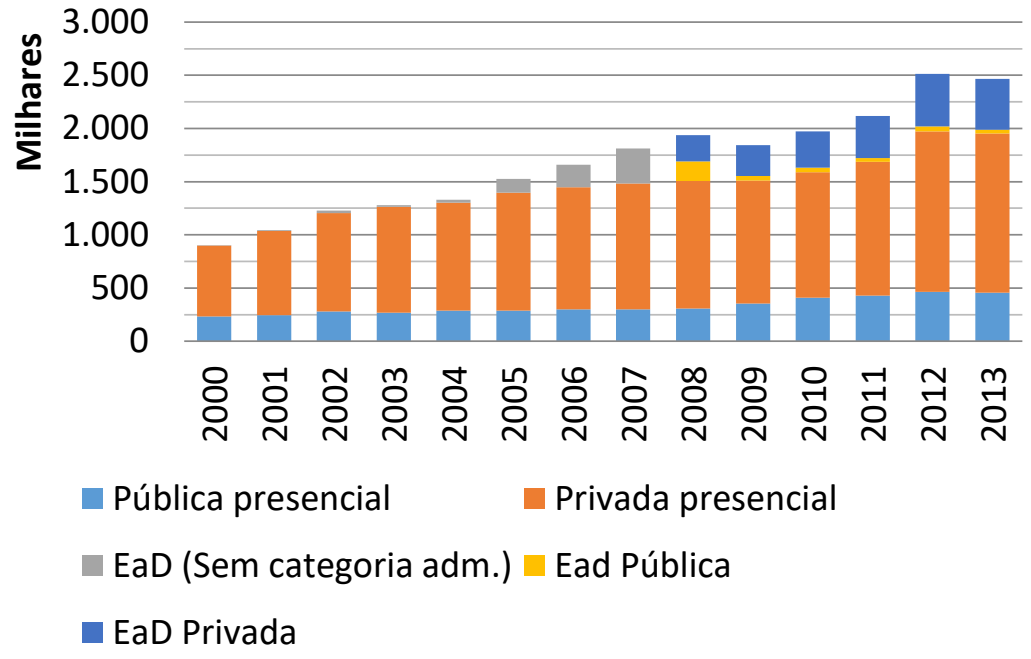

(Fonte: INEP)

O crescimento do número de ingressos, inferior ao de vagas, provocou o aumento da ociosidade, assunto que será debatido na próxima seção. Ao analisar o ano de 2009, observou-se uma forte redução do número de ingressos na modalidade a distância. Analisando-se o que ocorreu, encontrou-se que as informações fornecidas pelo INEP a partir de 2009 sobre o número de ingressantes nas IES embutiam profundas mudanças de metodologia (SILVA FILHO; MELO LOBO, 2012). Assim, é possível que a redução observada seja consequência da alteração metodológica, pois após o ano de 2009 o número de ingressos passou a se manter constante. Esse aspecto possivelmente foi consequência do modelo de educação a distância adotadono país, caracterizado pelo Sistema Universidade Aberta do Brasil, Lei no 5.800 (BRASIL, 2006). Nesse modelo, o governo federal financia, por meio de editais, universidades públicas para que ofertem vagas na modalidade a distância em polos de apoio presencial organizados por municípios e Estados participantes do Sistema. Ou seja, sem editais, o setor público deixa de crescer. O setor privado, por sua vez, não está atrelado ao sistema UAB. Isso permitiu seu crescimento, tal que em 2008 ele representava 87,0\% dos ingressos e em 2013 esse percentual subiu para $92,8 \%$.

Nos cursos de Licenciatura em Matemática houveram 305,4 mil ingressos. Destes, $73,2 \%$ o fizeram na modalidade presencial, a qual cresceu $38,6 \%$. A modalidade a distância, por sua vez, passou de 160 ingressos em 2001 para 8,2 mil ingressos em 2013, como pode ser visto na Figura 6. 
Figura 6 - Ingressos nos cursos de Licenciatura em Matemática no Brasil, segundo os anos e a modalidade de ensino.

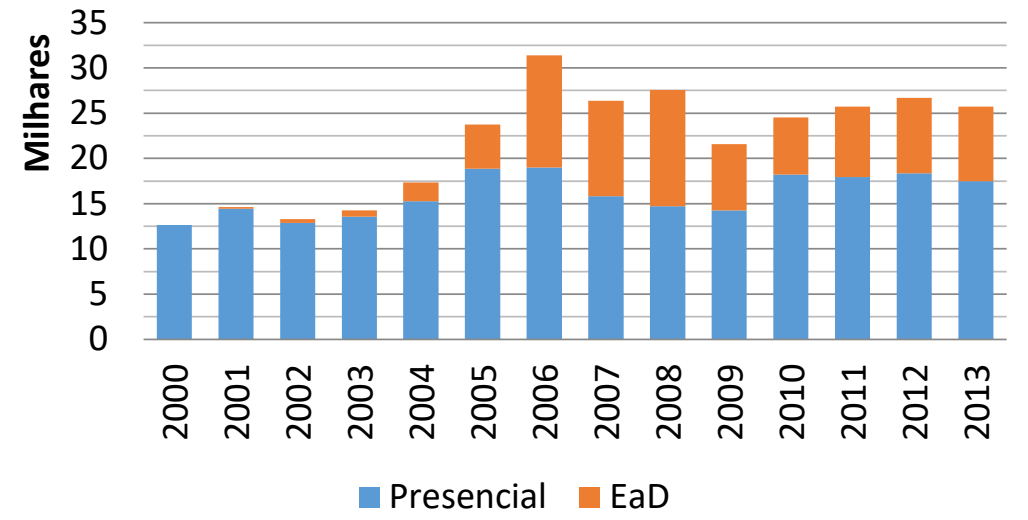

(Fonte: INEP)

A modalidade presencial apresentou taxa de crescimento de ingressos (igual a $38,6 \%$ ) inferior àquela observada para as vagas (igual a 97,6\%). Isso gera consequências que serão abordadas na próxima seção. Além disso, observou-se que enquanto as vagas sempre aumentaram, os ingressos variaram sem um padrão, tal que entre 2000 e 2006 houve crescimento, entre 2007 e 2009, redução, em 2010 os ingressos alcançaram o total de 18,2 mil alunos e depois passou a cair ininterruptamente. Sobre os cursos a distância, a situação é mais preocupante. Além do número de candidatos ter sido inferior ao total de vagas, nem todos ingressaram nos cursos, o que potencializa o problema das vagas ociosas.

\subsection{Vagas Ociosas}

Ficaram ociosas em todo o Brasil cerca de 22,1 milhões de vagas. Considerando a modalidade presencial, nas instituições públicas ficaram ociosas 481,5 mil vagas (9,5\% do total ofertado, com um crescimento igual a $447,7 \%$ ) e 15,1 milhões de vagas nas privadas $(49,2 \%$ do total ofertado, com um crescimento igual a 360,3\%). Na modalidade a distância, 8,6 milhões de vagas ficaram ociosas (72,0\% do total ofertado), como pode ser observado na Figura 7.

Figura 7 - Vagas ociosas em todos os cursos de nível superior no Brasil, segundo os anos, a modalidade de ensino e as categorias administrativas.

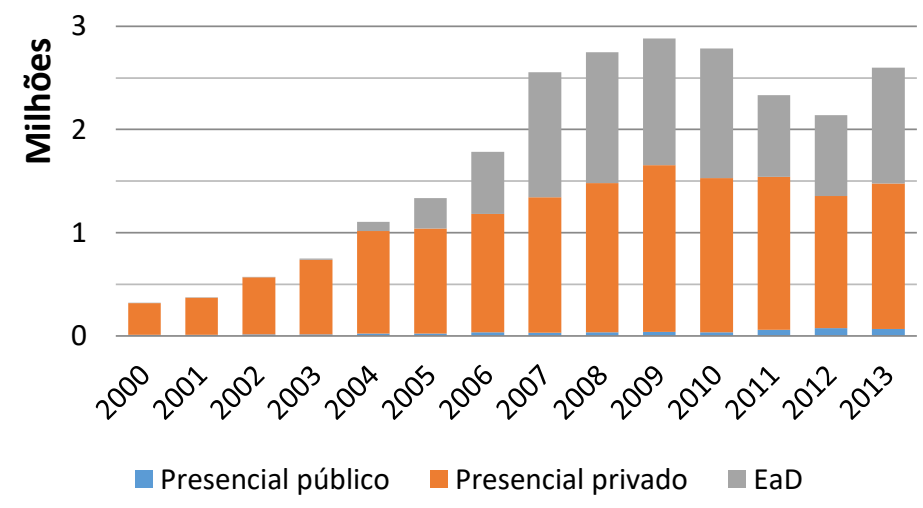

(Fonte: INEP) 
Nem todos os brasileiros com idade acima dos 18 anos de idade têm acesso à educação. E entre aqueles que estão estudando, não são todos que se encontram no ensino superior. A desigualdade racial e social é marcante nesse aspecto, pois afros descentes e jovens pobres têm menos acesso do que aqueles com maior renda ou que se autoconsideram brancos (TERRA, 2012). Portanto, em um país onde as oportunidades de acesso ao ensino superior são restritas, observar o crescimento de vagas ociosas, principalmente nas instituições públicas, é crítico. Na modalidade a distância, as estatísticas são piores. Os dados não permitem dimensionar quantas vagas ociosas foram financiadas com recursos públicos (seja nas instituições públicas ou privadas), mas quase $75 \%$ do total não foram preenchidas.

O total de vagas ociosas nos cursos de Licenciatura em Matemática foi igual a aproximadamente 608 mil (64,4\% do total). Destas, 38,0\% estão na modalidade presencial, com um crescimento de $257,0 \%$, tal que a ociosidade das vagas cresceu de $27,1 \%$ em 2000 para 48,8\% em 2013. Com relação ao total de vagas no período, $46,3 \%$ das vagas da modalidade presencial ficaram ociosas. Na modalidade a distância, o percentual foi igual a 79,4\%, como pode ser observado na Figura 8.

Figura 8 - Vagas ociosas nos cursos de Licenciatura em Matemática no Brasil, segundo os anos e a modalidade de ensino.

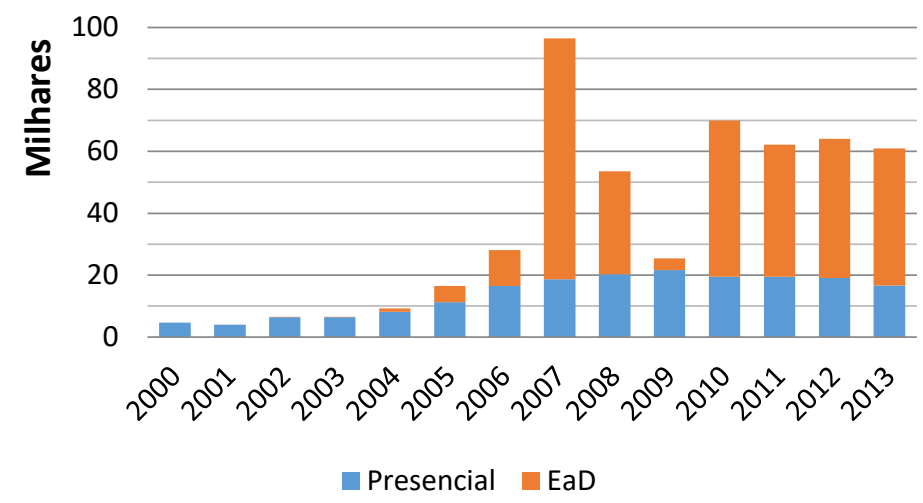

(Fonte: INEP)

Esses dados alertam que a políticas públicas para a formação de professores, pautadas na ampliação da oferta de vagas nos cursos de licenciatura, têm resultado no aumento da ociosidade. As vagas ociosas cresceram 6,7 vezes mais que o número de ingressos na modalidade presencial e na modalidade a distância o percentual foi semelhante àquele observado para todos os cursos de nível superior do país, tal que à cada 10 vagas, cerca de 8 não foram preenchidas.

\subsection{Matrículas}

O número de matrículas no ensino superior presencial aumentou 100,4\% nas instituições públicas e 142,1\% nas privadas. A modalidade a distância, que em 2000 tinha 1.682 alunos matriculados, em 2013 contava com 1,1 milhões de matrículas, das quais $13,4 \%$ estavam no setor público. Isso significa dizer que o país passou de 2,7 milhões de alunos matriculados no ensino superior para 7,3 milhões de 2000 a 2013, conforme pode ser visto na Figura 9. 
Figura 9 - Matrículas em todos os cursos de nível superior no Brasil, segundo os anos, a modalidade de ensino e as categorias administrativas.

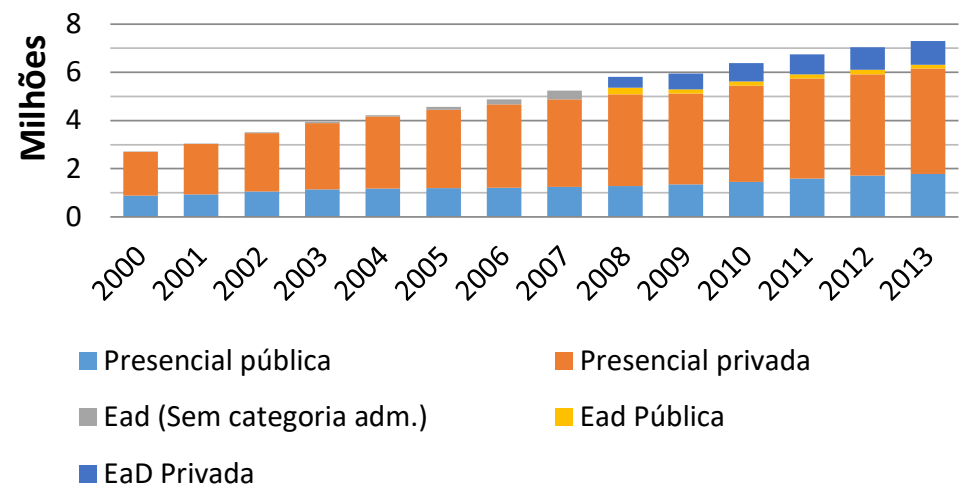

(Fonte: INEP)

O aumento observado do número de matrículas, apesar de necessário, não foi suficiente. Quase a metade da população brasileira ainda não terminou o ensino fundamental (aos 25 anos ou mais) e no outro extremo apenas $11,3 \%$ da população concluíram o ensino superior em 2012 (LEAL, 2012). O dado mais atual, publicado pela OCDE, mostra que apenas $14 \%$ dos brasileiros chegaram ao ensino superior, percentual inferior à média dos países membros da OCDE (35\%) ou de países latino-americanos como o Chile (21\%), Colômbia (22\%) e Costa Rica (23\%) (CANCIAN, 2016). Outro aspecto que merece destaque foi a redução progressiva do papel do Estado nas duas modalidades de ensino, ficando este limitado ao papel de financiar o ensino superior privado enquanto as universidades públicas carecem de recursos.

Sobre as matrículas nos cursos presenciais de Licenciatura em Matemática nas instituições públicas, foi possível observar um crescimento de $190,8 \%$ enquanto que a iniciativa privada teve uma redução de $24,8 \%$. Essas alterações fizeram com que na modalidade presencial o setor público aumentasse sua participação de 53,9\% em 2000 e para 81,9\% em 2013. A modalidade a distância, por sua vez, passou de 404 matrículas em 2002 para 33,6 mil matrículas, das quais 69,4\% encontravam-se no setor público, como pode ser visto na Figura 10.

Figura 10 - Matrículas nos cursos de Licenciatura em Matemática no Brasil, segundo os anos, a categoria administrativa e a modalidade de ensino.

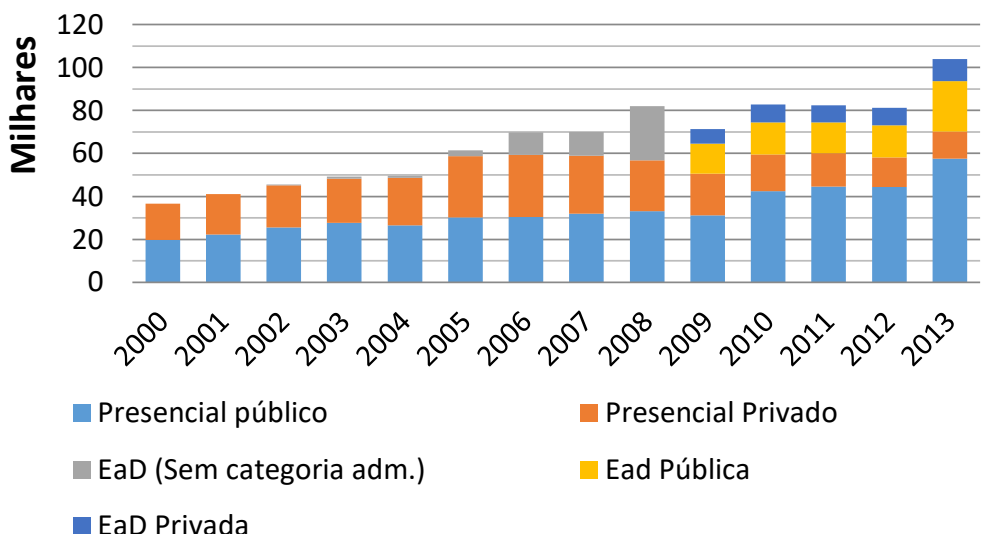

(Fonte: INEP) 
No âmbito dos cursos de formação de professores de matemática, a tendência de redução do papel do Estado observada no ensino superior não ocorreu. Pelo contrário. Nesse curso as instituições públicas foram responsáveis pela maioria das matrículas e a sua participação cresceu nos últimos anos. A falta de detalhes nos bancos de dados do INEP sobre as categorias administrativas das vagas e dos candidatos impedem análises mais detalhadas. Contudo, observou-se que a maioria das matrículas encontra-se no setor público e que o número de candidatos aos cursos de Licenciatura em Matemática teve, em 2009, o mesmo crescimento de candidatos às instituições públicas. Isso levanta a hipótese de que a maioria das vagas ofertadas nos cursos de Licenciatura em Matemática se encontra em instituições públicas. Confirmado essa hipótese, e constatado que a ociosidade de vagas no ensino superior público é relativamente pequena quando comparada com aquela observa na iniciativa privada, então será possível concluir que os cursos de formação de professores de matemática nas instituições públicas apresentam taxas de ociosidade alarmantes.

\subsection{Concluintes}

O ensino superior brasileiro emitiu cerca de 10,5 milhões de diplomas no período estudado. Cerca de $91,3 \%$ foram emitidos pela modalidade presencial, sendo que $23,8 \%$ foram de instituições públicas e $67,5 \%$, privadas. O crescimento dos concluintes nessa modalidade foi igual a $83,4 \%$ nas instituições públicas e a 193,8\% nas privadas. A modalidade a distância formou 460 pessoas em 2000 e 161,0 mil em 2013, tal que 14,3\% dos diplomas saíram das instituições públicas.

Figura 11 - Concluintes em todos os cursos de nível superior no Brasil, segundo os anos, a modalidade de ensino e as categorias administrativas.

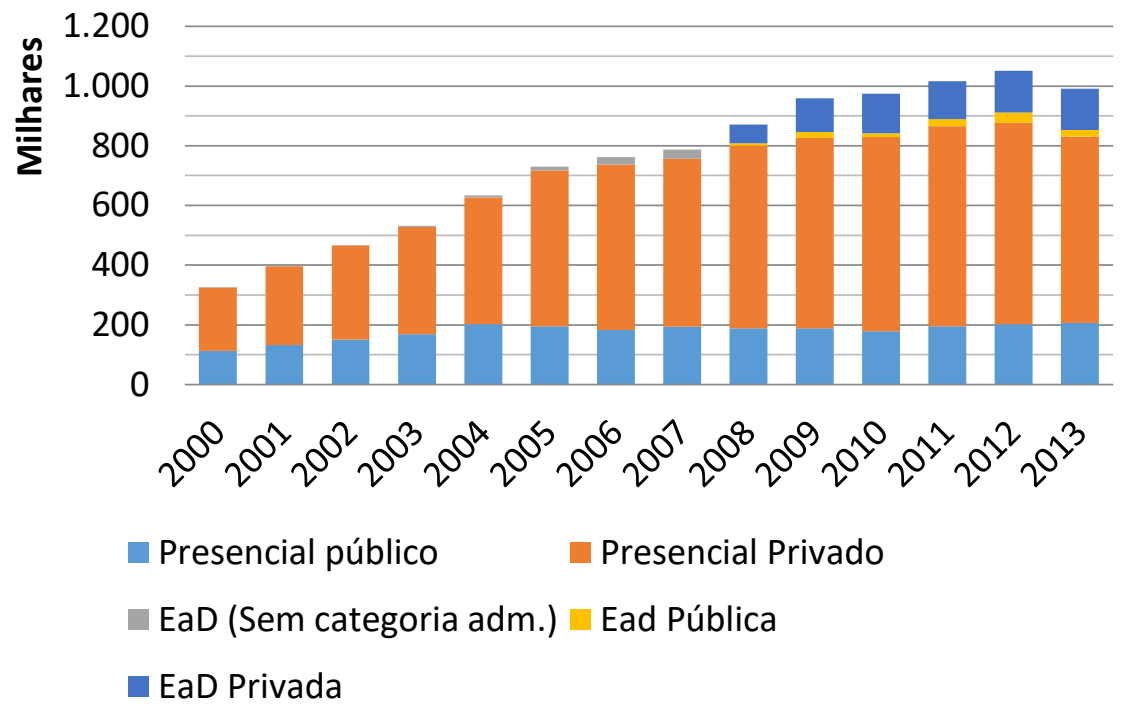

(Fonte: INEP)

Os cursos de Licenciatura em Matemática diplomaram 129,3 mil pessoas no período. A modalidade presencial representou $87,3 \%$ (com crescimento de $142,9 \%$ ), dos quais $44,5 \%$ são de instituições públicas (com crescimento de $288,9 \%$ ) e $42,8 \%$ de instituições privadas (com crescimento igual a $26,9 \%$ ). A 
modalidade a distância formou 180 pessoas em 2002 e 3,5 mil em 2013, sendo que nesse último ano $67,3 \%$ o fizeram em instituições públicas.

Figura 12 - Total de concluintes nos cursos de Licenciatura em Matemática no Brasil, segundo os anos, a categoria administrativa e a modalidade de ensino.

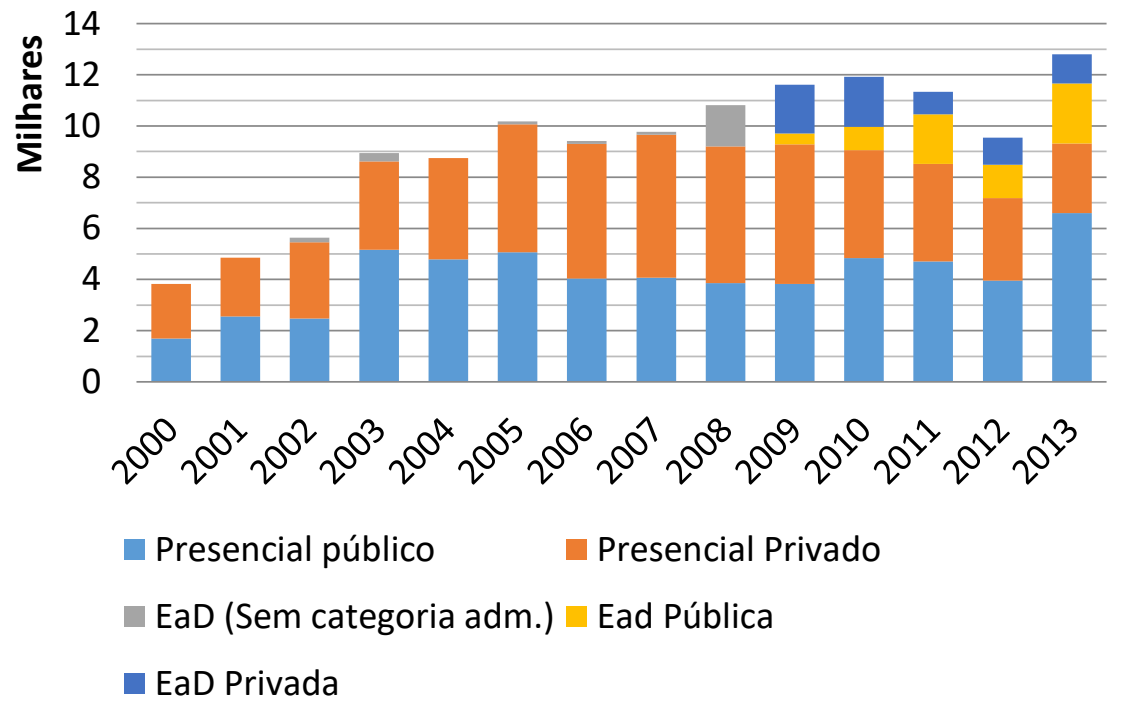

(Fonte: INEP)

No ano de 2000 o país estava formando menos de 4 mil professores de matemática. Em 2013, mais de 12 mil concluíram o curso (dos quais 9,3 mil na modalidade presencial). Para um país carente de oportunidades educacionais e de professores, ver triplicar o número de docentes de matemática formados traz um sentimento de que a educação está progredindo. No curso presencial, o crescimento de concluintes (igual a 142,9\%) foi maior que o crescimento de vagas $(97,6 \%)$ ou de ingressos (igual a 38,6\%), indicando que outros fatores têm interferido, positivamente, para a formação de professores de matemática. Como exemplo desses fatores é possível citar uma série de ações estatais voltadas para aumentar a permanência dos alunos no curso, tais como Ações Afirmativas e programas específicos voltados à formação de professores, como o Programa Institucional de Bolsas de Iniciação a Docência.

\subsection{Evasão}

Um problema importante para o ensino superior é a evasão. Muitas são as discussões sobre o conceito de evasão, as quais escapam do escopo do presente trabalho. O objetivo aqui foi apresentar as taxas de evasão calculadas com métodos presentes na literatura, visto que não há qualquer estatística sobre a mesma na base de dados do INEP. O primeiro resultado que se observa nas análises globais é a tendência de crescimento, independente do modelo matemático adotado. Outro aspecto é o seu valor médio, igual a 14,2\% (Lobo), 12,2\% (PROUNI) e $42,4 \%$ (OCDE), segundo os diferentes modelos matemáticas apresentados na metodologia. 
Figura 13 - Taxas de evasão média em todos os cursos presenciais de nível superior no Brasil, segundo os anos e os modelos matemáticos do Instituto Lobo, do PROUNI e da OCDE.

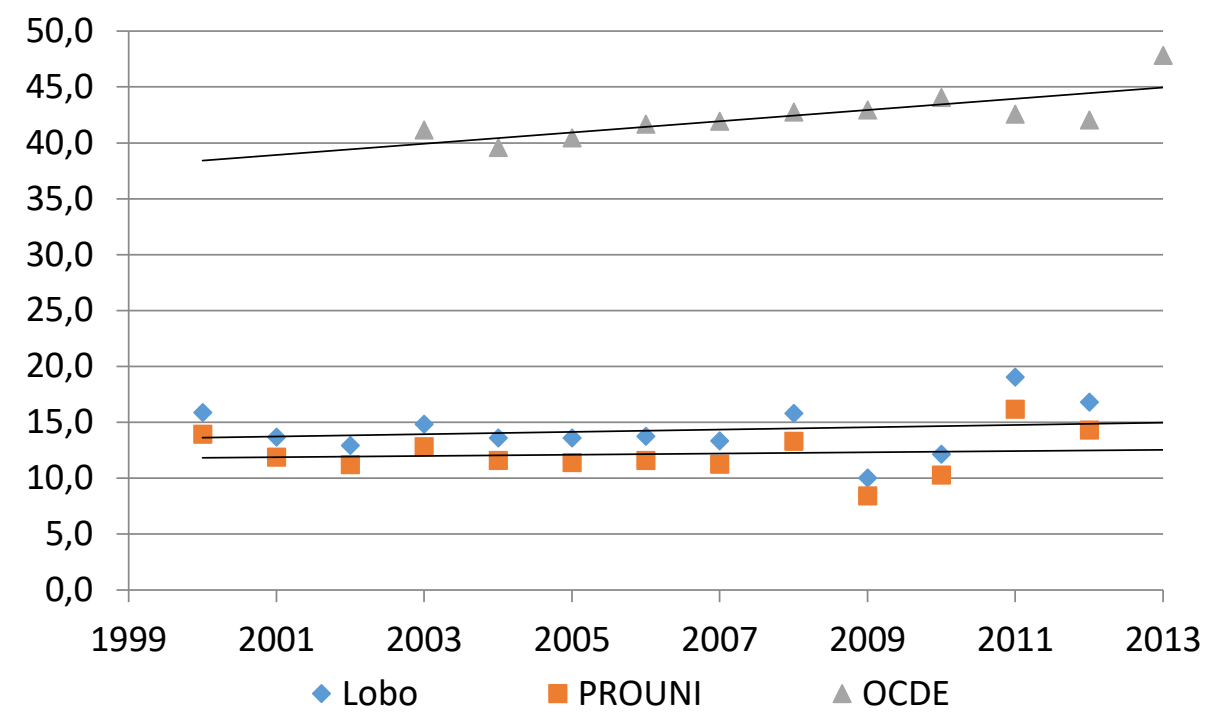

(Fonte: INEP)

Para o curso de Licenciatura em Matemática presencial, os percentuais médios das taxas de evasão foram iguais a 12,9\% (Lobo), 10,9\% (PROUNI) e 40,7\% (OCDE). As linhas de tendência dos modelos do instituto Lobo e PROUNI apresentam uma redução da evasão, consequência dos valores muito baixos nos anos de 2004, 2009 e 2012 (no gráfico eles foram zerados, mas os resultados apresentavam valores negativos). Já a linha de tendência obtida a partir do modelo matemático usado pela OCDE apresenta uma tendência de crescimento.

Figura 14 - Taxas de evasão média nos cursos presenciais de Licenciatura em Matemática, segundo os anos e os modelos matemáticos do Instituto Lobo, do PROUNI e da OCDE.

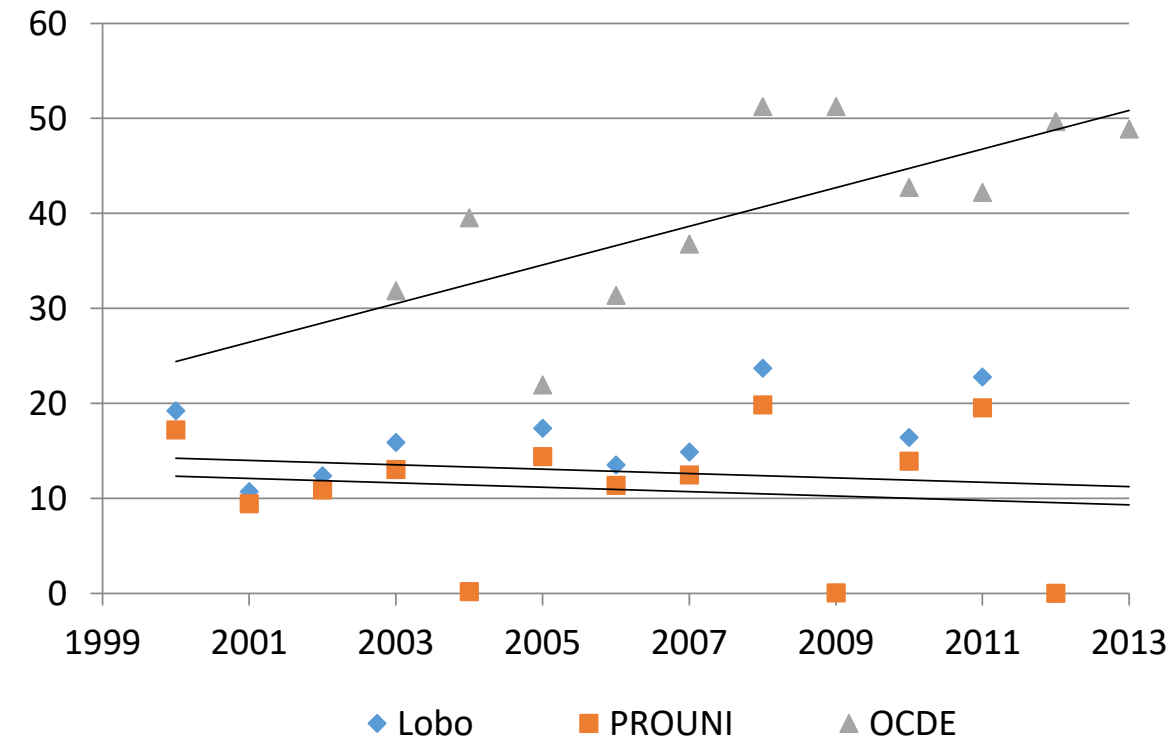


Como foi destacado previamente, em 2009 houve uma mudança metodológica do INEP na forma como determinados dados eram coletados e distribuídos. Essas alterações limitaram a análise quando se trata do estudo da evasão de alunos do ensino superior. Mas possivelmente isso pode explicar os valores muito baixos encontrados em 2009 e 2012, tal que se esses valores fossem desconsiderados, haveria uma tendência de crescimento. Por último, evitou-se o estudo da evasão na modalidade a distância porque ela é muito recente e houve um crescimento muito grande, tal que é mais interessante esperar alguns anos para se discutir, estatisticamente, essa questão.

\section{CONSIDERAÇÕES FINAIS}

Ao longo do trabalho buscou-se responder as questões de estudo apontadas na introdução. O início do século XXI foi caracterizado por uma série de políticas voltadas ao ensino superior e algumas delas tiveram os cursos de formação de professores como foco. Era esperado que os cursos de Licenciatura em Matemática tivessem, pelo menos, acompanhado o crescimento do ensino superior, mas isso não aconteceu. Não apenas a iniciativa privada cresceu mais, como também o setor público. Isto é, não houve investimentos para que os cursos de formação de professores de matemática sequer acompanhassem a ampliação do ensino superior brasileiro. Outro problema detectado foi a ampliação da ociosidade. Quase a metade das vagas nas instituições privadas não foram preenchidas e no setor público a quantidade de bancos vazios também cresceu. Contudo, nenhum deles observou a ociosidade encontrada nos cursos de Licenciatura em Matemática, igual a 64,4\%.

Considerando a diversidade de modelos encontrados na literatura para se calcular a evasão e a discrepância dos resultados encontrados, entende-se que são necessárias comparações das estimativas aqui apresentadas com dados empíricos para, assim, identificar aquele que pode melhor representar a evasão no ensino superior.

Outro aspecto que pode ser pontuado é o estudo da sala de aula. Formar licenciados não significa que as escolas terão docentes diplomados. Isto é, sabe-se que há uma evasão do profissional diplomado das salas de aula da educação básica que escapa das estatísticas discutidas nesse trabalho. É preciso uma política de atração desse diplomado, na forma de melhores condições de trabalho e salário. O que não acontece no momento atual, caracterizado por uma situação desfavorável para a manutenção dos melhores professores diante dos jovens brasileiros.

Por último, um ponto bastante positivo foi encontrado nas estatísticas sobre os concluintes. As ações voltadas para ajudar os alunos a se formarem têm tido resultados positivos, visto que o crescimento de concluintes foi maior que o de ingressos. Conclui-se esse trabalho apontando que essas políticas precisam ser ampliadas e aquelas voltadas para a ampliação de vagas nos cursos de licenciatura, repensadas. 


\title{
The numbers about degree in mathematics: focus on public policies
}

\begin{abstract}
The necessary expansion of basic education, carried out by Law 9,394 (BRAZIL, 1996), led the country to worrying statistics regarding the lack of teachers. In this context, this paper intends to present and discuss some data about the degree courses in Mathematics by means of the survey and the analysis of official documents for the accomplishment of a documentary research with quantitative approach. The data sources used were the Statistical Synopses of Higher Education, published by the National Institute of Studies and Research Anísio Teixeira (INEP / MEC). The data will be presented by means of graphs and the analyzes will make use of descriptive statistics. Data analysis points out that Brazilian higher education policy is supported by private initiative, that the Unified Selection System may be responsible for increasing candidates in public institutions and that the country has tripled the number of trained math teachers, a victory. However, while in the other upperlevel courses the country observes a small idleness of places in public institutions, in the degree courses the same does not happen. It was also observed that the dropout rates in the course of Mathematics Degree were high. Finally, we conclude that the expansion of teacher training courses did not occur in the case of mathematics, since its growth did not accompany the expansion of Brazilian higher education.
\end{abstract}

KEYWORDS: Teacher training. Mathematics Education. Public Policy for Education. 
1 Apoio CNPq.

\section{REFERÊNCIAS}

ARAUJO, R.S.; VIANNA, D.M. A história da legislação dos cursos de Licenciatura em Física no Brasil: do colonial presencial ao digital a distância. Revista Brasileira de Ensino de Física (Impresso), v. 32, p. 4403-1-4403-11, 2010.

BITTAR, M.; NOGUEIRA, R.G. Um Estudo da Criação e Desenvolvimento de Licenciaturas em Matemática na Universidade Federal de Mato Grosso do Sul. Bolema, Rio Claro (SP), v. 29, n. 51, p. 263-283, abr. 2015,

BRASIL. Conselho Nacional de Educação. Parecer CNE/CES 1.302/2001. Diretrizes Curriculares Nacionais para os Cursos de Matemática, Bacharelado e Licenciatura. 2001.

BRASIL. Decreto no 5.800, de 08 de junho. Dispõe sobre o Sistema Universidade Aberta do Brasil - UAB. 2006. Disponível em: $<$ http://www.planalto.gov.br/ccivil_03/_Ato20042006/2006/Decreto/D5800.htm> Acesso em 24 nov. 2015.

BRASIL. Lei № 5.540, de 28 de novembro. Fixa normas de organização e funcionamento do ensino superior e sua articulação com a escola média, e dá outras providências. 1968. Disponível em: <https://www.planalto.gov.br/ccivil_03/leis/15540.htm>Acesso em 24 de nov. 2015.

BRASIL. Lei no 5.692, de 11 de agosto. Fixa diretrizes e bases para o ensino do 10 e 2o grau, e dá outras providências. 1971. Disponível em:

<https://www.planalto.gov.br/ccivil_03/leis/15692.htm>Acesso em 24 de nov. 2015.

BRASIL. Lei № 9.394, de 20 de dezembro. Estabelece as diretrizes e bases da educação nacional. Diário Oficial da República Federativa do Brasil, Brasília: DF, v. 134, n. 248, dez.196. Seção I, p.27834-27841. 1996a. Disponível em: < https://www.planalto.gov.br/ccivil_03/Leis/L9394.htm > Acesso em 15 abr. 2010.

BRASIL. Ministério da Educação. Parâmetros Curriculares Nacionais: Ciências da Natureza, Matemática e suas Tecnologias. Brasília: Ministério da Educação, 2000. Disponível em: <http://portal.mec.gov.br/seb/arquivos/pdf/ciencian.pdf> Acesso em 15 abr. 2010. 
CANCIAN, N. Só $14 \%$ dos adultos brasileiros têm ensino superior, diz relatório da OCDE. Folha de São Paulo. São Paulo, 27 jun 2017. Educação. Disponível em: <https://mail.google.com/mail/u/0/\#search/ABNT/143937931fb47cb4>. Acessado em 27 jun 2017.

FIORENTINI, D. A Pesquisa e as Práticas de Formação de Professores de Matemática em face das Políticas Públicas no Brasil. Bolema, Rio Claro (SP), V.21, no 29, 2008, pp. 43 a 70.

FLORES, C.R.; ERN, E.; TANEJA, I.J.; SILVAI, T. avaliação de cursos de licenciatura em física e matemática a distância: um modelo possível. Avaliação, Campinas, Sorocaba, SP, v. 15, n. 2, p. 183-200, jul. 2010.

JUNQUEIRA, S.M.S.; MANRIQUE, A.L. Reformas curriculares em cursos de licenciatura de Matemática: intenções necessárias e insuficientes. Ciênc. Educ., Bauru, v. 21, n. 3, p. 623-635, 2015.

LEAL, L.N. Só 11,3\% da população adulta têm faculdade, diz IBGE. Estadão. São Paulo, 19 dez 2012. Disponível em:

<http://www.estadao.com.br/noticias/geral,so-11-3-da-populacao-adulta-temfaculdade-diz-ibge,975640>. Acesso em 27 jun. 2017.

NUNES RC. Panorama geral da Evasão e Retenção no Ensino Superior no Brasil (IFES). In: Encontro Nacional de Pró-reitores de Graduação, XXVI. Anais... Recife: MEC. 2013. [acesso 12 Fev 2014]. Disponível em: http://www.forgrad.com.br/apresentacoes/dia1/2013\%20\%20Painel\%20Forgrad\%20Agosto\%20-\%20Evasao.pdf

SANTOS FILHO, J.R.; CHAVES, V.L.J.; MORAIS, E.S. Políticas de financiamento do ensino superior privado pela via de renúncia fiscal. In: Jornada internacional de políticas públicas, VII. Anais... São Luís: Universidade Federal do Maranhão. 2015. Acesso em: <http://www.joinpp.ufma.br/jornadas/joinpp2015/pdfs/eixo13/politicas-definanciamento-do-ensino-superior-privado-pela-via-de-renuncia-fiscal.pdf>

SBPC. Sugestões para a formação de professores da área científica para escolas de 1o. e 2o. graus. Ciência e Cultura. V.33, n.3, 369-77. 1981.

SILVA FILHO, R.L.L.; LOBO; M.B.C.M. Como a mudança na metodologia do INEP altera o cálculo da evasão. Instituto Lobo. 2012. Acesso: < http://www.institutolobo.org.br/imagens/pdf/artigos/art_079.pdf> 
TERRA. IBGE: em 10 anos, triplica percentual de negros na universidade. Acesso em: <http://noticias.terra.com.br/educacao/ibge-em-10-anos-triplica-percentualde-negros-na-

universidade,4318febb0345b310VgnCLD200000bbcceb0aRCRD.html>

Recebido: 2016-02-07

DOI: $10.3895 /$ rbect.v11n1.3739

Como citar: ARAUJO, R.; VIANNA, D. M. Os números da licenciatura em matemática: políticas públicas em foco. Revista Brasileira de Ensino de Ciência e Tecnologia, v. 11, n. 1, 2018. Disponível em: <https://periodicos.utfpr.edu.br/rbect/article/view/3739>. Acesso em: xxx.

Correspondência: Renato Araujo - raraujo.brasil@gmail.com

Direito autoral: Este artigo está licenciado sob os termos da Licença Creative Commons-Atribuição 4.0 Internacional.

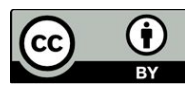

